\title{
La construcción identitaria española en el Segundo Imperio y las exposiciones universales de 1855 y 1867
}

\author{
Sergio Fuentes Milà
}

\author{
LA CONSTRUCCIÓN IDENTITARIA ESPAÑOLA EN EL SEGUNDO IMPERIO \\ Y LAS EXPOSICIONES UNIVERSALES DE 1855 Y 1867
}

\begin{abstract}
Resumen
Este trabajo se centra en el análisis de la imagen oficial de España en el marco de las exposiciones universales organizadas por el Segundo Imperio francés (1885 y 1867). Las tensiones entre el visage deseado desde la corte napoleónica y la sociedad parisina de una España pintoresca, gitana y árabe frente al perfil oficial que ofrece el Estado, es una de las problemáticas más complejas en relación con las cuestiones identitarias y de representatividad nacional a través del arte del mundo contemporáneo. El análisis de las representaciones nacionales de 1855 y 1867 a través de los objetos artísticos expuestos y otros casos complementarios (pintura y arquitectura básicamente) aporta una comprensión más precisa de la imagen de España en la segunda mitad del siglo XIX y de su construcción identitaria. El perfil de una España popular y castiza en 1855 se contrapone al de una España imperial y triunfal en la muestra de 1867, generando discursos recurrentes que se alternarán en los diferentes certámenes internacionales de la segunda mitad del siglo XIX.
\end{abstract}

\section{Spanish Identitary Construction During the Second Empire AND THE UNIVERSAL EXHIBITIONS OF 1855 AND 1867}

\begin{abstract}
This paper considers an analysis of the official image of Spain within the context of the Universal Exhibitions organized by the Second French Empire (those of 1855 and 1867). The tension that arose between the notion of Spain desired by the Napoleonic court and Parisian society - picturesque, gypsyish, Arabic - and the official profile promoted by the Spanish state, is one of the most complex issues relating to identity and national representation through art of the contemporary world. An analysis of the national representations displayed through art at the 1855 and 1867 exhibitions and other complementary cases (mainly painting and architecture), provides a clearer picture of the image of Spain in the second half of the nineteenth century and her identitary construction. The characterization of a popular and castiza Spain in 1855 contrasted heavily with the triumphant, imperial Spain of 1867, generating recurring discourses that would appear alternately at the various international exhibitions of the second half of the nineteenth century.
\end{abstract}


FUENTES MiLÀ, S., «La construcción identitaria española en el Segundo Imperio y las exposiciones universales de 1855 y 1867", Acta/Artis. Estudis d'Art Modern, 4-5, 2016-2017, págs. 77-87

PALABRAs Clave: Exposición Universal 1855, Exposición Universal 1867, identidad nacional, Segundo Imperio, España isabelina

KEYWORDS: Universal Exhibition 1855, Universal Exhibition 1867, national identity, Second Empire / Elizabethan Spain

El presente trabajo sintetiza algunas de las ideas ya analizadas en otros estudios, ${ }^{1}$ además de servir de punto de partida para la ampliación de la problemática en torno a la representatividad de España en las exposiciones universales organizadas por el Segundo Imperio francés (1855 y 1867). La limitación del marco cronológico y político responde al hecho de que fueron los primeros actos internacionales de este tipo que tuvieron sede en París y que, además, no pueden comprenderse sin el respaldo de la corte imperial napoleónica. Precisamente, las relaciones del núcleo de poder bonapartista con las instituciones españolas encargadas de ocuparse de la sección nacional de sendas muestras definieron la fisonomía representativa del Estado con el fin de fijar el lugar que este debía ocupar en la jerarquía internacional. La subordinación de España a los dictados estéticos e ideológicos de Francia refuerza que la nación, mediante el arte, adoptara una imagen exótica donde el tópico del torero, la flamenca y el bandolero se erigió como la principal seña diferenciadora. No obstante, en el segundo certamen, la España isabelina optó por consolidar y reforzar fórmulas más tradicionales donde se otorgaba el protagonismo al pasado imperial de los siglos XV y XVI para, de este modo, reclamar el rol de potencia histórica. Seleccionaremos algunos de los instrumentos que sirvieron para fijar ambos visages de lo español, además de apreciar la efectividad que estos tuvieron sobre el público coetáneo y en la red de relaciones de poder.

Como punto de partida, cabe señalar que las relaciones entre Francia y España durante el Segundo Imperio eran verdaderamente fructíferas. Los vínculos colaborativos entre Napoleón III e Isabel II fueron un aspecto que debe tenerse en cuenta aquí tanto a nivel institucional como personal (la participación de España en la empresa francesa de México es un ejemplo). En la figura de la emperatriz Eugenia de Montijo, de ascendencia española, íntima de la reina y estrechamente relacionada con los aristócratas españoles, radica una importancia capital para comprender el éxito de lo español en una corte tan sofisticada como la francesa. A todo ello, la tradición de los viajeros románticos de finales del siglo XVIII y primera mitad del xIX servía de base para construir desde la Francia imperial una imagen de España parcial, mágica e imaginada, basada en lo que seducía al público galo, esto es, el exotismo andaluz casi árabe y los tipos hispánicos (flamenca, torero y bandolero, entre otros) como personificaciones ajenas a los procesos de modernización europea. Aunque ligeramente anterior al contexto imperial, un ejemplo de esta confluencia entre la tradición romántica y la corte napoleónica es, sin duda, Prosper de Mérimée y su gusto por lo español encarnado en obras coloristas como Carmen (1845), además de poderosas familias españolas que en el núcleo parisino cercano a la emperatriz se encargaban de consolidar estas directrices diferenciadoras y limitadoras sobre la representatividad de España. Ciertamente, Carmen cristalizó la imagen del rêve espagnol por

1. Parte de la base de esta investigación es el resultado de diversos estudios realizados por Nuria Peist y Sergio Fuentes Milà de la Universidad de Barcelona; Fuentes MiLÀ, S.; PeIst, N., «Supremacía y subordinación del arte español en las exposiciones universales de París e Internacional de Buenos Aires (1855-1910)», en Alsina Galofré, E.; Beltrán CatALÁN, C. (eds.), El reverso de la Historia del Arte: exposiciones, comercio y coleccionismo en los siglos (1850-1950). Gijón: Trea, 2015, págs. 141-157. 
parte del público francés. ${ }^{2}$ El círculo de poder napoleónico servía de filtro y difundía esta imagen de lo español a un público mucho más general (también la imagen de otros países), concretando un imaginario colectivo donde España se erigía como una marca de lo africano en Europa y era consumida como un espectáculo curioso y mero divertimento a partir de los rasgos diferenciales mencionados.

La construcción del perfil que debía tener cada una de las naciones dentro del orden internacional era un claro ejercicio de imposición política. Precisamente en ese marco de identidades construidas y, en ocasiones, hiperbolizadas en detrimento de la realidad, es donde hallamos el fenómeno de las primeras exposiciones universales del siglo XIX, verdadero instrumento de reunión armónica pero a la vez de diferenciación y jerarquización de naciones. Tras el gran éxito cosechado en la primera muestra (Londres, 1851), Napoleón III consideró que organizar un acontecimiento de estas características sería el escenario perfecto para consolidar el recientemente instaurado Segundo Imperio y demostrar al mundo su prestigio, así como su carácter pacificador. De hecho, esta primera exposición debía ser una fiesta de naciones al servicio de la construcción del régimen francés erigido como L’Empire de la Paix, según la denominación del propio emperador.

Ligado a dicha idea recuperamos también el concepto de vision planétaire propio del bonapartismo del tercer Napoleón y extraído del Mémorial de Sainte-Hélène. El principal objetivo era que Francia recuperase el lugar de privilegio dentro del panorama internacional. En su texto Des idées napoléoniennes, Napoleón III insiste: «lidée napoléonienne n'est point une idée de guerre mais une idée sociale, industrielle, commerciale, humanitaire». ${ }^{3}$ A partir de la organización de actos internacionales como las exposiciones universales, la superioridad de Francia se consolidaba en todos los campos, permitiendo ilustrar el rol de Grande Nation del siglo XIX, soberana del resto de los pueblos y responsable máxima de todas las producciones del ser humano. ${ }^{4}$ Además, la Exposición servía para remarcar la importancia de la «marca Francia» y su superioridad dentro de la disciplina industrial y también la artística. El año 1855 fue escogido para el primer acto, conmemorando los cuarenta años de paz tras Waterloo. Una década después, en 1867, Napoleón III organizó una muestra mucho más espectacular y completa en la capital, en este caso para ilustrar la consolidación de su proyecto político, aunque sin saber que tres años después la guerra con Prusia lo destronaría.

\section{LA REAFIRMACIÓN DEL TÓPICO ESPAÑOL EN LA SECCIÓN DE PINTURA DE 1855}

Debemos advertir, como indica Peist, que las obras de arte, y sobre todo la pintura, cumplían dos funciones complementarias y correlativas en el tiempo en la segunda mitad del siglo XIX dentro del marco de las exposiciones universales. Por un lado, los objetos artísticos eran, con la arquitectura de pabellones nacionales, los símbolos culturales del proceso de definición y construcción de las especificidades y las identidades de los pueblos en un contexto internacional. Más tarde, a finales del siglo XIX, las obras de arte experimentarían un proceso de homo-

2. Hoffmann, L., Romantique Espagne. L'image de l'Espagne en France entre 1800 et 1850. París: Les Presses Universitaires de France, 1961, pág. 90.

3. NAPOLEón III, Euvres de Napoléon III. 1. L'Idée napoléonienne. Des Idées napoléoniennes. Fragments historiques: 1688 et 183o. Réponse à M. de Lamartine. Rêveries politiques. Mélanges. París: Plon, 1856, pág. 172.

4. AnCEAu, É., Napoléon III: un Saint-Simon à cheval. París: Tallandier, 2008, págs. 245-273 y 363-366. 
geneización manifestada en el dominio formal (el abandono de la mimesis) además de en el campo de los contenidos simbólicos de la pintura tradicional (abandono de la historia, las temáticas nobles y los tópicos nacionales que veremos en el caso español en las exposiciones universales de 1855 y 1867, a favor del nuevo interés por la representación de los acontecimientos de la vida contemporánea). ${ }^{5}$

No obstante, en los casos que nos ocupan, España siempre se mostró al mundo a través del objeto pictórico de una manera muy clara, remarcando sus especificidades a partir del tópico castizo y propio, símbolo e instrumento de diferenciación y construcción de su identidad nacional. En este sentido, el costumbrismo pictórico presentado en la muestra de 1855 se consolidaría a través de una selección de obras que no tenían otro objetivo más que el de presentar la España que esperaba y deseaba la Francia imperial. La evidente subordinación al gusto del público parisino a partir del exotismo fundamentado en los tópicos andaluces y, a lo sumo, en el casticismo castellano, pretendía contentar al público internacional y, a su vez, diferenciar la «marca España» del resto de los países, revitalizando las visiones que tanto se habían empeñado en difundir los viajeros románticos franceses e ingleses desde finales del siglo XviII. Así pues,

la presencia de este tipo de pintura se consolidó en las primeras exposiciones universales de París [...]. Tales soluciones pictóricas potenciaron significativamente la imagen exótica de España a partir de unos tipos específicos, [...] una España parcial, única y centrada en lo andaluz y lo pintoresco. ${ }^{6}$

De las ochenta telas españolas presentadas en 1855, las temáticas fueron variadas y siempre priorizando las predilectas por el público parisino: tauromaquias, escenas costumbristas, paisajes y retratos de la aristocracia española, ${ }^{7}$ principalmente, aunque también se presentaron pinturas de historia que pasaron casi desapercibidas. Incluso se hallaban fórmulas que mezclaban los retratos de la nobleza con la estética costumbrista mencionada, fundiendo los dos géneros más habituales de la producción hispánica. Un par de ejemplos fueron las obras de López La princesa de Asturias en traje andaluz y La nodriza de la princesa de Asturias vestida de pasiega.

Toros y flamenco a grandes dosis - principalmente lo primero- presidían el muro español. ${ }^{8}$ Un buen ejemplo de ello es Patio de caballos antes de la corrida de Manuel Castellano (ilustración 1). Las fisonomías y poses castizas de los personajes que pueblan estos lienzos están al servicio de la tradición y lo propio del lugar como elementos únicamente españoles que el espectador debía reconocer rápidamente, asociándolos al concepto «España». Esta limitación del país y de la plasmación de lo nacional a ciertas regiones y a tópicos que no respondían en absoluto a la realidad global de España acentuó la crítica por parte de ciertos sectores, principalmente progresistas, hacia este tipo de representación metonímica. Aunque fuera años después y refiriéndose tanto a la Universal de 1855 como a la de 1867, Frontaura criticaba el abuso de los tópicos españoles en la representación nacional, sentenciando que «en España hay más

5. PeIst, N., «Las exposiciones universales y la definición del objeto artístico español», en Socias BATET, I. (ed.), Nuevas contribuciones en torno al mundo del coleccionismo de arte en los siglos XIX y XX. Gijón: Trea, 2013, pág. 333. Véase también, PEIst, N., El éxito en el arte moderno. Trayectorias artísticas y proceso de reconocimiento. Madrid: Ábada, 2012.

6. Fuentes Milà, S.; Peist, N., «Supremacía y subordinación...».

7. En la sección española, el género del retrato fue uno de los más apreciados, tanto por los personajes representados como por estar casi monopolizado por el ya reputadísimo Federico Madrazo, que presentó catorce telas, entre las que destacaron La condesa de Vilches, S.M. la reina Isabel II, La duquesa de Alba o La duquesa de Medinaceli. El éxito cosechado le reportó ser el único español que consiguió la Medalla de Primera Clase de 1855.

8. Entre otras muchas obras, se hallaban telas de Juan José Martínez de Espinosa, como Caballos muertos en la corrida de toros o Picadores ensayando con sus caballos, y de Eugenio Lucas Velázquez, como Peleas de toros en Madrid. Deben mencionarse otros ejemplos como Una feria de Sevilla de Joaquín Domínguez Bécquer o lienzos sobre procesiones de Jenaro Pérez Villamil. 


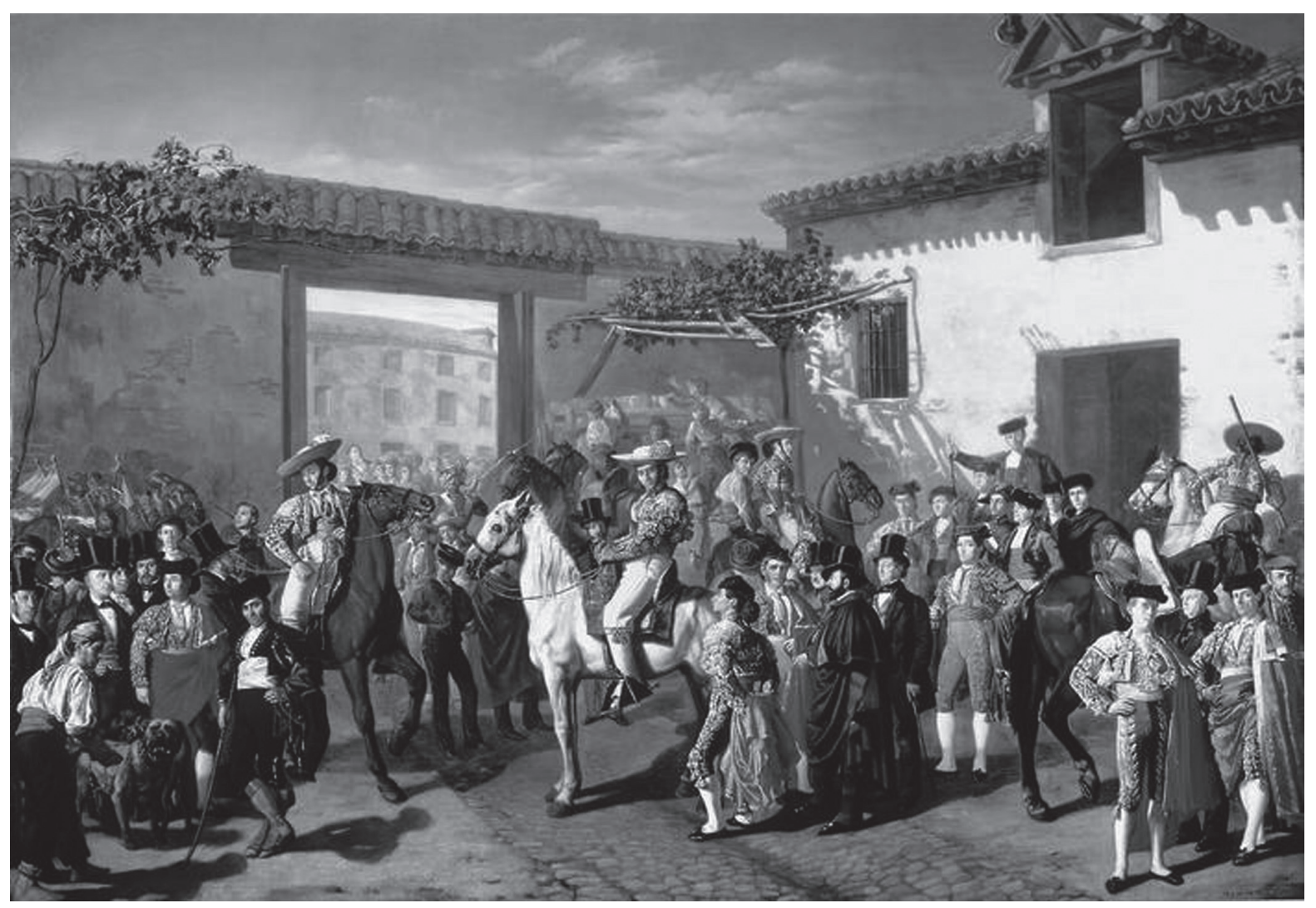

que manolas y toreros». ${ }^{9}$ En la misma línea, el archiconocido comentario de Ochoa es una muestra de la oposición a la obsesiva reiteración de los tópicos y del pintoresquismo español desde España, donde se muestra además el deseo de que el país sea representado en su totalidad y con sus realidades, no limitado a escenarios que se construyan a partir de los tipos esperados por el público internacional y presentados, incluso, como una caricaturización tanto efectiva como efectista:

Ciertas exageraciones de lo que hoy se llama colorido local y antes se llamaba carácter, que deben dar á los extranjeros una triste idea de la raza andaluza: las caras y sobre todo las actitudes de los personajes en ellos representados, mas que de hombres, parecen de monos [...]. Ruego á los franceses y sobre todo á las francesas que no vean en ese échantillon tan desgraciado el verdadero tipo nacional. Somos mejores que eso, por mas que digan ó mas bien, por mas que pinten lo contrario. ${ }^{10}$

A pesar de ceder a los dictados de Francia, el éxito fue relativo según los expertos debido a que las temáticas eran ya repetitivas en exceso y no aportaban nada nuevo e interesante, más que la consolidación de esa España parcial, pintoresca y «esperada». Por ello, Du Camp sentencia duramente que «en matière artistique, les États-Unis d'Amérique n'existent pas encore et l'Espagne n'existe plus», a lo que añade posteriormente: "L'Italie, comme l'Espagne, deux pays catholiques ultramontains, ne peuvent plus compter comme nations artistiques» por sus escasas aportaciones. ${ }^{11}$

9. Frontaura, C., Viaje cómico a la Exposición de París. París, 1868, pág. 234.

10. ОсноA, E., París, Londres y Madrid. París: Baudry, 1861, pág. 52.

11. Du Camp, M., Les Beaux-Arts à l'Exposition Universelle de 1855. París: Librairie Nouvelle, 1855, págs. 340 y 398.

1. Manuel Castellano Patio de caballos antes de la corrida, 1853, óleo sobre tela, $168 \times 245 \mathrm{~cm}$. Museo Nacional del Prado, Madrid. 


\section{ARQUITECTURA EFÍMERA: EL NEOPLATERESCO COMO «VISAGE» DE LA ESPAÑA IMPERIAL}

Otro punto interesante para analizar la imagen oficial ofrecida por España a través de los lenguajes artísticos en el contexto que nos ocupa, es el de la arquitectura de pabellones de 1867 (en la Universal de 1855 todavía no se había creado esta tipología expositiva de éxito). El objetivo de los pabellones nacionales consistía en plasmar el espíritu de cada país a partir de un perfil arquitectónico determinado, propio y diferencial. ${ }^{12}$ En este sentido, «la elección de ciertos estilos arquitectónicos por parte de cada nación ejercía de verdadero instrumento para insistir en el rol que cada país jugaba dentro de la jerarquía internacional». ${ }^{13}$ Según Kaufman, la disposición del Champ de Mars de la Exposición Universal de 1867 fue el primer museo de arquitectura donde se podían encontrar edificios completamente construidos y de nueva planta diseñados exprofeso. ${ }^{14}$ La reunión de arquitecturas nacionales se convertía en un verdadero tour de force entre los países participantes a partir de una fisionomía específica y diferenciadora. Según la forma y la disposición del edificio, el Estado conseguía irrumpir en la sensibilidad del espectador con la finalidad de ilustrar el génie national. De esta manera, mediante los pabellones asistimos a un juego de reivindicaciones identitarias en forma de arquitecturas como lenguaje artístico y, sobre todo, entre los estilos que mejor representaban la imagen nacional oficial. ${ }^{15} \mathrm{La}$ mezcla de estilos y de referencias ofrecía la experiencia de viajar tanto en el tiempo como por los diferentes países participantes,$^{16}$ así como el ejercicio de clasificar las naciones por orden de importancia y según sus relaciones políticas históricas y actuales respecto al resto.

En el caso específico, la Comisión Oficial Española erigió dos edificios propios: un pabelón nacional en estilo neoplateresco y una horchatería valenciana, situados los dos en el quartier allemand del Champ de Mars. De los dos, el más significativo fue el primero (ilustración 2), proyectado por Jerónimo de la Gándara, arquitecto y miembro de la representación española de la muestra de 1867. El estilo escogido condicionaba la definición del país, verdadero componente diferenciador al servicio de lograr una imagen nacional determinada: una revisión historicista del lenguaje arquitectónico plateresco del siglo XVI, es decir, neoplateresco. De hecho, el modelo concreto, extraído del repertorio de monumentos nacionales de la época y utilizado por el arquitecto De la Gándara, fue el Palacio de Monterrey de Salamanca. La elección del estilo mencionado y la marginación del estilo neoárabe para la representación oficial española se sustentaba en el objetivo de rememorar la época imperial del siglo xvi liderada por el Reino de Castilla. De este modo, la comisión nacional de 1867 reclamaba un pasado donde España se había convertido en el país más importante de la jerarquía internacional. España se mostraba como una nación equiparable al Imperio francés y al Imperio británico a través del episodio histórico y su materialización mediante las formas arquitectónicas, «como muestra de los tiempos caba-

12. Sobre la evolución estilística y los discursos políticos e identitarios de los pabellones españoles, véase BuENO, M., Arquitectura y Nacionalismo. Pabellones españoles en las exposiciones universales del siglo XIX. Málaga: Universidad de Málaga, 1987; idem, «Arquitectura y nacionalismo. La imagen de España a través de las exposiciones universales», Fragmentos, 15-16, 1989, págs. 58-70; idem, «Arquitectura como ideología. Los pabellones españoles vistos a través del discurrir de la política», en BARTH, V., et al., Movimiento Expo. Las exposiciones universales y la aportación española. Madrid: Metáfora, 2008, págs. 80-97. Además de otros títulos ya mencionados, véase también, SAZATORNIL, L.; LASHERAS, A., «París y la españolada. Casticismo y estereotipos nacionales en las exposiciones universales de París (1855-1900)", Mélanges de la Casa de Velázquez, 35-2, 2005, págs. 265-290.

13. Fuentes Milà, S., «Los pabellones de España en la Exposición del Centenario de la Independencia argentina. La búsqueda de un perfil arquitectónico moderno", en Socias BATET, I. (ed.), El arte hispánico en las exposiciones internacionales. Circulación, valores y representatividad. Milán: Hugony, 2014, pág. 71.

14. Kaufman, E., «The Architectural Museum from World's Fair to Restoration Village», Assemblage, 9, 1989, pág. 22.

15. NoRmand, A., L'Architecture des nations étrangères: Étude sur les principales constructions du parc à l'Exposition Universelle de Paris de 1867. París: Morel, 1870.

16. Rimmel, E., Recollections of the Paris Exhibition of 1867. Londres: Chapman and Hall Piccadilly, 1868, págs. 23-43.

$82-$ ARTiCles 


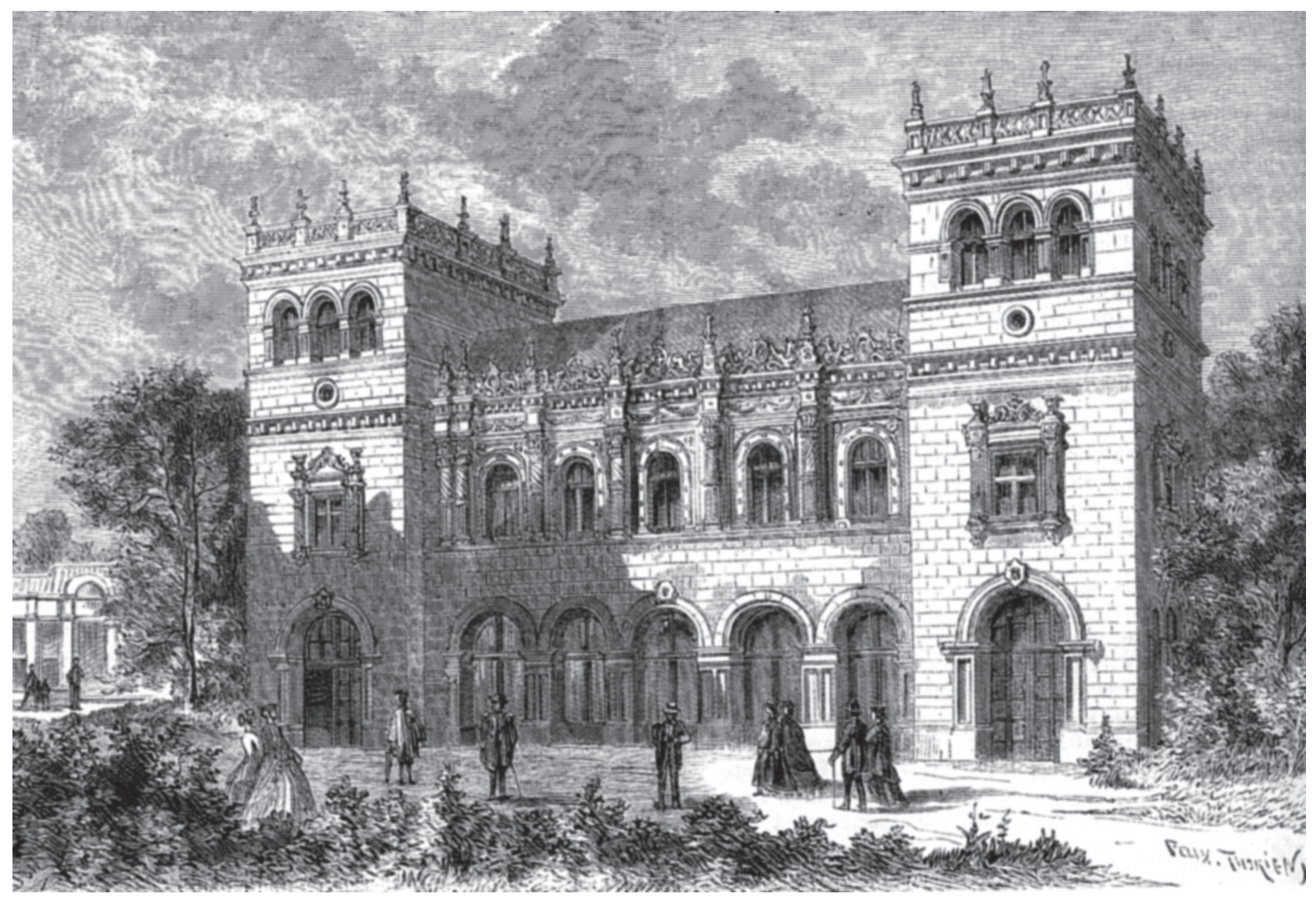

llerescos de Castilla». ${ }^{17}$ Se redundaba en la dimensión simbólica e identitaria del pabellón, puesto que «da una idea de la grandeza y del poder de España en aquellos tiempos en que el sol nunca se ponía en sus dominios, y del grado de esplendor que entonces alcanzaban las artes». ${ }^{18}$

Gautier y Blanchard, representantes de la crítica francesa, comprendieron la intención de De la Gándara de recuperar el pasado triunfal de una España casi olvidada en la jerarquía europea del siglo XIX, en detrimento del exotismo que esperaba el público internacional. El primero afirmaba que «ce édifice avec ses deux tours carrées, ses larges portes, ses élégantes fenêtres et les statuettes qui le couronnent, est plus qu'un pavillon, c'est presque un monument», un monumento al pasado glorioso de la nación. ${ }^{19}$ Por otro lado, Blanchard insistía también en la monumentalidad para remarcar la importancia del Estado respecto a los demás países mediante este ejercicio de imposición física y estilística dentro del «musée architectural» de $1867 .^{20}$

A pesar de la finalidad triunfalista, la elección del neoplateresco fue muy criticada y mal comprendida por parte del público en general. En esta línea, es importante recordar la visión exótica que la sociedad del Segundo Imperio esperaba de España. Este enfoque se traducía a nivel arquitectónico en un lenguaje arabizante. Lo cierto es que cuando se pensaba en España se hacía, como dijimos ya, de manera parcial, materializándose en ejemplos concretos como la Alhambra de Granada o la Giralda de Sevilla, entre otros. Por ello, para el pabellón nacional de 1867 se aguardaba que el país se mostrase al mundo mediante el uso del neoárabe, generan-
2. Jerónimo de la Gándara Pabellón español para la Exposición Universal de París de 1867, grabado para España en París. Crónica de la Exposición Universal de 1867, de José Castro y Serrano. Madrid: Durán, 1867, pág. 8.

17. CAStro, J., «Casa de España», España en París. Crónica de la Exposición Universal de 1867, 1, 1867, pág. 7.

18. «Pabellón de España», El Museo Universal, 5 de mayo de 1867, págs. 138-139.

19. Gautier, H., Les curiosités de l'Exposition Universelle de 1867. París: C. Delagrave et Cie., 1867, pág. 46.

20. «[Ce pavillon espagnol] est un souvenir de ces remarquables monuments, trop peu connus, dont la renaissance des arts a dotéa la péninsule»; BLANCHARD, P., «Exposition Universelle de 1867. VII, le pavillon espagnol et le pavillon portugais», L'Illustration Journal Universelle, 16 de marzo de 1867, pág. 170. 
do una tensión entre la imagen esperada y la ofrecida desde el aparato oficial (lo exótico subordinador versus lo imperial hegemónico) y desafiando al imaginario colectivo decimonónico que asociaba España con una estética morisca.

\section{«TANTO MONTA, MONTA TANTO»: EL ÉXITO DE LA PINTURA DE HISTORIA EN 1867}

Si mediante la arquitectura España reivindicaba la imagen de una nación poderosa, imperial y soberana histórica de la cultura europea, el mismo objetivo primó en la selección de obras para la sección de pintura de la muestra de 1867. Mediante el lenguaje pictórico asistimos al rescate de un pasado glorioso de una nación impositiva que pretendía recordar al resto del mundo que ella fue una de las principales responsables de la evolución de la cultura hegemónica occidental, siempre bajo la concepción eurocentrista del siglo XIx. En definitiva, España deseaba ocupar el lugar de privilegio perdido en la jerarquía internacional, así como suprimir el estigma de país exótico y casi africano, difundido por la cultura preeminente francesa. A partir de esta premisa, los grandes formatos de pintura de historia se convirtieron en las principales obras a destacar, verdaderos responsables en la configuración de la imagen de la España imperial y triunfal del pasado en el siglo xIx. Por este motivo, la identidad nacional española estaba sustentada en la recuperación de las gestas y, sobre todo, de los eminentes personajes de la época de los Reyes Católicos que se convertían en tipos históricos que encarnarían el país: ${ }^{21}$ Isabel la Católica, Juana la Loca, el episodio del descubrimiento de América por Cristóbal Colón, la evangelización de los nuevos territorios durante el siglo xvI, etc. Mediante los cuadros de historia se ofrecía una imagen precisa del Estado español que se utilizaba para afianzar el poder político monárquico, así como para la construcción identitaria. ${ }^{22}$ El éxito de estos productos artísticos a favor de la exaltación nacional asentaba que

desde los medios oficiales se tratase de regularizar la participación española tanto por el posible uso político en el interior [exposiciones nacionales] como por el prestigio exterior [exposiciones universales]. ${ }^{23}$

En la muestra de 1867, España aportó sesenta y tres cuadros según fuentes oficiales, ${ }^{24} \mathrm{o}$ cincuenta y cuatro según la prensa coetánea. ${ }^{25}$ De todos ellos, constatamos la relevancia de la obra de Eduardo Rosales, un cuadro que ilustra la idea de identidad nacional que venimos presentando y que centralizó el muro español: Doña Isabel la Católica dictando su testamento (ilustración 3 ) ${ }^{26}$ Se trata de una gran pintura de historia en la que se representa el momento de

21. Rincón, W., «Los Reyes Católicos en la pintura española del siglo XIX», Arbor, Ciencia, Pensamiento y Cultura, CLXXVIII, 701, 2004, págs. 129-161.

22. Peist, N., «Las exposiciones...», pág. 337; ReYero, C., «El reconocimiento de la Nación en la historia. El uso espaciotemporal de pinturas y monumentos en España", Arbor, Ciencia, Pensamiento y Cultura, CLXXVIII, 740, 2009, págs. $1197-1210$.

23. GutiÉRREZ, J., Exposiciones Nacionales de Pintura en España en el siglo XIX. Madrid: Universidad Complutense de Madrid, 1987, pág. 150.

24. Exposición Universal de 1867. Catálogo General de la Sección Española. París: Comisión Regia de España, 1867, págs. 117-120.

25. CAstro, J., «Obras de arte», España en París. Crónica de la Exposición Universal de 1867, 3, 1867, pág. 47.

26. En 1865, tras el gran éxito del cuadro durante la Exposición Nacional de Bellas Artes celebrada en Madrid en 1864 , el Estado español adquirió la pieza; GutıÉRREz, J., «Las adquisiciones oficiales en las exposiciones nacionales de bellas artes en el siglo XIX», en Socias BATET, I. (ed.), Nuevas contribuciones..., pág. 180. 


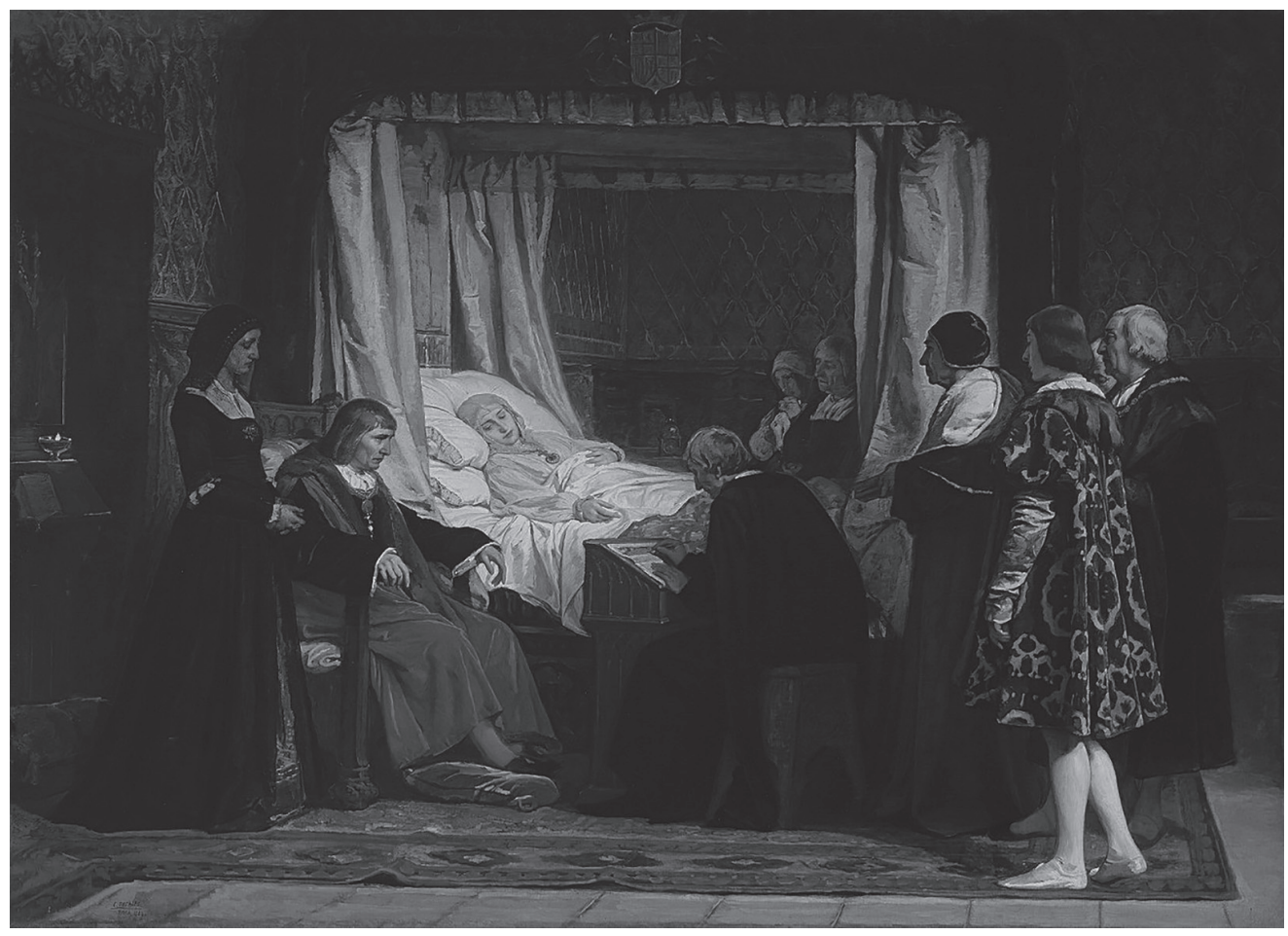

3. Eduardo

Rosales

Isabel la Católica dictando su testamento, 1864 , óleo sobre tela, $280 \times 400 \mathrm{~cm}$. Museo Nacional del Prado, Madrid.

la muerte de Isabel la Católica, que aparece en su cama dictando su testamento en Medina del Campo (1504). El rescate de esta tipología de personajes solemnes e históricos fue fomentado por la Academia española a partir de los premios de las exposiciones nacionales y de su adquisición por parte del Estado. Con el gran acontecimiento que suponía la Exposición Universal de 1867, esta estrategia identitaria e ideológica se internacionalizaba con el fin de presentar al mundo la «marca España».

Debemos añadir que en la segunda mitad del siglo XIX la temática habitual de los Reyes Católicos debe interpretarse como un instrumento simbólico asimilado como el primer nacionalismo español en la historia, la unión política además de territorial. ${ }^{27}$ Pero la construcción de dicho nacionalismo estaba al servicio de establecer una relación directa entre el gobierno conservador del momento y el de la época histórica representada, así como de mostrar el vínculo entre la reina de 1867 , Isabel II, y la célebre reina del siglo $x V .{ }^{28}$ Sobre la predilección del personaje de la reina, afirma que viene justificada por la homonimia entre las dos soberanas: la Isabel del presente y la del pasado. De hecho, esta analogía se consolidó cuando Isabel II asumió el poder en España en 1833. En este sentido, el cuadro de Vicente López La reina Isabel la Católica guiando a su nieta, la princesa Isabel, al Templo de la Gloria (1833) es un claro ejemplo. ${ }^{29}$ En 1858 José Güell publicó Paralelo entre las reinas católicas doña Isabel I y doña Isabel II, ${ }^{30}$ un

27. Álvarez, J., «España y su laberinto identitario», en Colom, F. (dir.), Relatos de Nación. La construcción de las identidades nacionales en el mundo hispano. Madrid: Iberoamericana, 2005, págs. 463-475; PÉREZ, J., «Memoria, historia y poder. La construcción de la identidad nacional española», en CoLoM, F. (dir.), Relatos..., págs. 697-727.

28. En este sentido, no es casualidad que en el muro de la sección española se diese protagonismo tanto al cuadro de Rosales como al único retrato que presentó para la ocasión Madrazo, Retrato de S.M. la reina Isabel II de España. De esta manera, el mensaje político a través del objeto artístico se exhibía de manera evidente al espectador que observaba aquella España pintada, donde a través de la historia moderna se reforzaba el reinado de los Borbones coetáneos.

29. DíEz, J., «Isabel la Católica en la pintura de historia del siglo XIX», en MANso PorTo, C. (coord.), Isabel la Católica y el arte. Madrid: Real Academia de la Historia, 2006, págs. 100-101.

30. GÜELL, J., Paralelo entre las reinas católicas doña Isabel I y doña Isabel II. París: Jules Clayé, 1858. 
texto que tenía el objetivo de consolidar esta unión. ${ }^{31}$ Además, la reina de Castilla servía para reafirmar la preeminencia del sector castellano en la construcción nacional española del siglo XIX..$^{32}$ Esta obra es un ejemplo evidente de la utilización de la pintura de historia desde España para definir al Estado hispánico contemporáneo ${ }^{33}$ y consolidar el poder político de la monarquía de los Borbones en un panorama internacional erigido y promovido por la vision planétaire bonapartista.

El éxito cosechado por la tela fue notable tanto oficialmente como «á los ojos del público y de la crítica, y ha caracterizado quizá como ninguna obra la escuela española en París», afirmaba Castro. ${ }^{34}$ Otras telas de la sección oficial como el Desembarco de los puritanos en América del Norte de Antonio Gisbert o el Primer desembarco de Colón en el Nuevo Mundo de Dióscoro Puebla, recuperan la gesta imperial española, puesto que mostraban a la nación como la responsable de instruir e iluminar a los nuevos territorios descubiertos. Así, los rasgos plasmados son los de un imperio constructivo, culturalizador, alejado de las gestas militares y las masacres contra los pueblos autóctonos.

En cuanto a otros géneros pictóricos presentes en la sección española, al igual que en 1855, se encontraba el paisaje. En el caso de 1867, el paisaje en ocasiones estuvo supeditado a espacios simbólicos ligados a la historia de los personajes anteriormente mencionados. Un ejemplo paradigmático - cosa que demuestra su vinculación con la tendencia de representatividad general politizada - fue la obra de Pablo Gonzalvo Interior de la Capilla Real de Granada y sepulcros de los Reyes Católicos. Por otro lado, los cuadros del tipo español que con tanto éxito fueron acogidos en la muestra parisina de 1855 , en la de 1867 ya no se presentaban como la marca y seña de España, sino casi como meros ornamentos costumbristas a modo de remplissage, supeditados a la potencia simbólica de la España oficial histórica e imperial de los siglos XV y XVI, materializada a partir de las grandes telas de historia, con el cuadro de Rosales como máximo exponente centralizador.

A pesar de presentar la problemática de manera sintética y centrándonos en el objeto artístico (ejemplos clave pictóricos y/o arquitectónicos), se observa qué imagen ofreció España al mundo dentro del marco escenográfico que supusieron las dos exposiciones universales organizadas por Napoleón III. Apreciamos una imagen cambiante, que en ocasiones cede a los dictados de la sociedad francesa bonapartista, donde lo andaluz y lo exótico se erigen como marca y seña identitaria de lo español, mientras que en otros casos opta por un perfil mucho más solemne y suntuoso, rescatando la época de los Reyes Católicos y el descubrimiento de América. La subordinación de España a los dictados de Francia en la muestra de 1855 pretendía asegurar un éxito mayor de aceptación y asociación nacional mediante el arte, a través del mencionado exotismo donde el tópico del torero, la flamenca y el bandolero se convirtieron en temas predilectos. En el polo opuesto, en la Universal de 1867, la España isabelina hizo uso de fórmulas artísticas más tradicionales con el episodio imperial de los siglos XV y XVI como marco refe-

31. En el caso francés advertimos ciertas similitudes en la misma época. Durante el Segundo Imperio, una de las temáticas de representación predilecta para la pintura de historia fue la recuperación de episodios de la epopeya de Napoleón I. Con la inclusión de estos contenidos, se establecía una analogía entre Napoleón III y su antecesor y fundador de la dinastía Bonaparte. El arte y la representatividad nacional francesa a través de escenas históricas napoleónicas servían para consolidar y justificar el poder del tercer Napoleón, sobrino del primero, además de para recuperar un triunfalismo del que la Francia de los cincuenta y sesenta del siglo XIX carecía. Entre algunos de los artistas encargados de desarrollar esta estrategia convertida en tendencia artística como representación de lo nacional francés bonapartista, destacamos a Meissonier, quien presentó en la Universal de 1867 su célebre tela Campagne de France 1814 y cosechó gran éxito con Napoléon à cheval, que fue una de las obras más reproducidas. En una línea similar, también cabe mencionar a Gérôme y sus series pictóricas sobre Bonaparte y la Expedición a Egipto (1798).

32. PÉREZ, T., «Imágenes, historia y nación. La construcción de un imaginario histórico en la pintura española del siglo XIX», en ColOM, F. (dir.), Relatos..., pág. 1131.

33. Sobre esta cuestión, ReYERo, C., «El reconocimiento de la Nación...»; e idem, París y la crisis de la pintura española, 1799-1889: del Museo del Louvre a la Torre Eiffel. Madrid: Universidad Autónoma de Madrid, 1993.

34. Castro, J., «Cuadros de Arte», España en París. Crónica de la Exposición Universal de 1867, 8, 1867, pág. 118. 
rencial protagonista, reclamando así un rol de potencia internacional que hacía siglos había perdido. Esta contraposición - y a veces intersección de visages - queda ilustrada en el diagrama de Venn generado a partir de la especificidad y la cantidad de aparición de los temas y estilos que centralizan la producción artística española presentada en 1855 y 1867.

Con el estudio del caso español, apreciamos que las muestras internacionales concretas resultaron de especial interés y de suma importancia para comprender cómo sería presentada España oficialmente en el resto de las exposiciones universales de la segunda mitad del siglo XIX. Incluso se continuará con la alternancia de ambos perfiles en muestras de principios del xx, ya sea en París o en otros escenarios urbanos y políticos: por un lado, la España árabe, exótica, de fantasía y ensueño (Viena 1873, París 1878 o Bruselas 1910, entre otros); por el otro, la España imperial, colonizadora, poderosa y capaz de difundir la cultura occidental en el Nuevo Mundo (por ejemplo, París 1900 o Buenos Aires 1910). Para cada una de estas fórmulas, los lenguajes artísticos, así como la elección de las piezas que se mostrarían, fueron adaptados y, por lo general, sucumbieron a la repetición de modelos específicos y codificados, fácilmente reconocibles en el imaginario colectivo a favor de la imagen de representatividad deseada. 